\title{
Lise Gauvin (dir.), Les littératures de langue française à l'heure de la mondialisation
}

Jean François Plamondon

\section{OpenEdition}

1 Journals

\section{Édition électronique}

URL : http://journals.openedition.org/studifrancesi/6112

DOI : 10.4000/studifrancesi.6112

ISSN : 2421-5856

Éditeur

Rosenberg \& Sellier

\section{Édition imprimée}

Date de publication : 1 mai 2011

Pagination : 217-218

ISSN : 0039-2944

\section{Référence électronique}

Jean François Plamondon, « Lise Gauvin (dir.), Les littératures de langue française à I'heure de la mondialisation », Studi Francesi [En ligne], 163 (LV | I) | 2011, mis en ligne le 30 novembre 2015, consulté le 13 janvier 2021. URL : http://journals.openedition.org/studifrancesi/6112 ; DOI : https:// doi.org/10.4000/studifrancesi.6112

Ce document a été généré automatiquement le 13 janvier 2021.

\section{(c)}

Studi Francesi è distribuita con Licenza Creative Commons Attribuzione - Non commerciale - Non opere derivate 4.0 Internazionale. 


\title{
Lise Gauvin (dir.), Les littératures de langue française à l'heure de la mondialisation
}

\author{
Jean François Plamondon
}

\section{RÉFÉRENCE}

LISE GAUVIN (dir.), Les littératures de langue française à l'heure de la mondialisation, Montréal, Hurtubise, 2010, pp. 183.

1 Les textes réunis sous ce titre ont été d'abord présentés lors du $26^{\mathrm{e}}$ Colloque des écrivains, organisé par l'Académie des lettres du Québec, dont Gauvin est la présidente. Reconnue par ses pairs comme une spécialiste des littératures francophones, Lise GAUVIN a su réunir pour cet ouvrage des noms d'auteur prestigieux qui livrent un témoignage sur leur rapport à la francophonie. Et ce rapport, Gauvin le ressent problématique et voit dans le préfiguré des écrivains francophones l'impossibilité de se sortir du «non-poème» pour reprendre l'expression de Gaston Miron. Elle affirme à cet égard que «chaque écrivain doit jusqu'à un certain point réinventer la langue» mais que «la situation des écrivains francophones a ceci de particulier que le français n'est pas pour eux un acquis, mais plutôt le lieu et l'occasion de constantes mutations et modifications» (p. 21). Lancée sur cette idée de la réinvention de la langue qui touche à la fois le texte et son auteur, elle continue plus loin en affirmant que «le texte littéraire francophone s'appuie sur des glissements de langue qu'il doit s'inscrire d'une façon ou d'une autre dans la poétique du roman, glissements qui deviennent aussi, dans certains cas, comme chez Chamoiseau, mais aussi chez Ducharme, une interrogation sur les frontières entre vérité et fiction» (p. 27).

2 Jean-Marie Gustave LE CLÉzio, qui inaugurait ce colloque, lance les travaux en affirmant que le français est bien plus qu'une langue. Dans cette ode à l'idiome qu'il travaille brillamment, le Prix Nobel 2009 rappelle que la langue française appartient autant aux 
ex-colonies qu'à la France elle-même. Le «français est beaucoup plus qu'une langue. Il est un lieu d'échanges et de rencontres. Ses frontières se sont dissoutes dans la totalité du monde, ce qui ne signifie pas un déracinement ni une vulnérabilité, mais au contraire une plus grande liberté, une audace et une résonance nouvelles. Par une sorte de justice immanente, ce sont ceux qui ont souffert de l'oppression, ce sont ceux qui ressentent, comme au Québec, la menace de la mondialisation à l'anglaise, qui sont aujourd'hui les plus ardents défenseurs de notre langue» (p. 41). S'ensuit une liste de noms d'auteurs francophones qui couvrent les cinq continents, énumération qui démontre que derrière un grand écrivain se cache toujours un insatiable lecteur. C'est d'ailleurs aussi sur le problème de la lecture que s'attarde d'abord la formidable communication du dramaturge Olivier KEMEID qui souligne que le petit peuple québécois, qui ne compte que sept millions d'habitants, ne suffit pas à faire vivre ses écrivains, et si «c'est le cas pour le Québec, inutile de s'étendre sur des contrées comme le Liban et, tiens, l'Acadie, où l'attribution du Goncourt à Antonine Maillet lui a permis de se faire connaitre non pas en France (Antonine qui?) mais dans son propre pays» (p. 71). Poursuivant sa logique et son discours sur la réception, Kemeid n'hésite pas à considérer le classicisme français comme le responsable de la tiédeur de l'accueil d'un certain nombre d'œuvres originales inspirées d'un baroque aussi efficace que non désiré en Ile-de-France. «La résistance française - plus forte que celle de 1940, mais ceci est une autre histoire -, c'est le refus des multiples usages de la langue française, c'est la marche victorieuse de la langue classique, celle des maîtres et non des valets, qui depuis Rabelais n'a pas connu de grands chambardements, mis à part l'ermite de Meudon...» (p. 74). Ce vibrant appel au souvenir de Rabelais comme l'un des grands auteurs de la langue française sert à l'auteur à démontrer que si l'œuvre de Réjean Ducharme n'a pas eu l'accueil qu'elle aurait dû recevoir, c'est que l'auteur québécois appartient aux enfants de Rabelais et non aux descendants de Molière.

Pour sa part Dany LAFERRIÈRE refusera une fois de plus de s'insérer dans la famille des écrivains de la francophonie, des écrivains délimités par un territoire. À la manière d'un Barthes qui prétend qu'écrire est un verbe intransitif, Laferrière est un écrivain refusant tout qualificatif qui l'astreindrait à un lieu, à un courant. Il est écrivain point. Paul CHAMBERLAND, que l'on retrouve avec grand bonheur, rend hommage à Aimé Césaire et à Gaston Miron, sans doute ses deux plus grandes inspirations. On comprend mal en final l'intervention de Jean-Daniel LAFOND, auteur, cinéaste et époux de la chef d'état du Canada. Certes, Lafond venait à la fois rendre hommage à Aimé Césaire et au passage, sur un ton intimiste, à la représentante d'Elisabeth II au Canada, son épouse Michaëlle Jean. Heureusement court, cet article cherche à redorer par procuration une image ternie par des symboles hautement coloniaux en terre québécoise. Cela n'apporte rien au travail de ses collaborateurs et renverse d'une certaine manière l'hommage qu'il voulait rendre au grand homme que fut Césaire, père de toutes les décolonisations. À cet égard, je serais fort étonné que Césaire eût accepté de siéger en prince consort sur le trône de France. Mais cela est de la politique-fiction et ce qui intéresse cette rubrique est plutôt le véritable monde de la fiction: la littérature! 